\title{
Investigating the Relationships of P3b with Negative Symptoms and Neurocognition in Subjects with Chronic Schizophrenia
}

\author{
Giulia M. Giordano ${ }^{1, \dagger}{ }^{\dagger}$ Andrea Perrottelli ${ }^{1,+}$, Armida Mucci ${ }^{1, *}$, Giorgio Di Lorenzo ${ }^{2} \mathbb{D}$, Mario Altamura ${ }^{3}$, \\ Antonello Bellomo ${ }^{3}$, Roberto Brugnoli ${ }^{4}$, Giulio Corrivetti ${ }^{5}$, Paolo Girardi ${ }^{4}$, Palmiero Monteleone ${ }^{6}(\mathbb{D}$, \\ Cinzia Niolu ${ }^{2}$, Silvana Galderisi ${ }^{1}$, Mario Maj ${ }^{1}$ and The Italian Network for Research on Psychoses $\ddagger$
}

1 Department of Psychiatry, University of Campania “Luigi Vanvitelli”, 80138 Naples, Italy; giuliamaria.giordano@unicampania.it (G.M.G.); andrea.perrottelli@unicampania.it (A.P.); silvana.galderisi@unicampania.it (S.G.); mario.maj@unicampania.it (M.M.)

2 Department of Systems Medicine, University of Rome "Tor Vergata", 00133 Rome, Italy; di.lorenzo@med.uniroma2.it (G.D.L.); niolu@med.uniroma2.it (C.N.)

3 Psychiatry Unit, Department of Clinical and Experimental Medicine, University of Foggia, 71122 Foggia, Italy; mario.altamura@unifg.it (M.A.); antonello.bellomo@unifg.it (A.B.)

4 Department of Neurosciences, Mental Health and Sensory Organs, S. Andrea Hospital, University of Rome “La Sapienza”, 00189 Rome, Italy; roberto.brugnoli@uniroma1.it (R.B.); paolo.girardi@uniroma1.it (P.G.)

5 Department of Mental Health, University of Salerno, 84133 Salerno, Italy; corrivetti@gmail.com

6 Section of Neurosciences, Department of Medicine, Surgery and Dentistry, 'Scuola Medica Salernitana', University of Salerno, 84081 Salerno, Italy; pmonteleone@unisa.it

Citation: Giordano, G.M.; Perrottelli, A.; Mucci, A.; Di Lorenzo, G.; Altamura, M.; Bellomo, A.; Brugnoli, R.; Corrivetti, G.; Girardi, P.; Monteleone, P.; et al. Investigating the Relationships of P3b with Negative Symptoms and Neurocognition in Subjects with Chronic Schizophrenia. Brain Sci. 2021, 11, 1632. https:// doi.org/10.3390/brainsci11121632

Academic Editors: James A Waltz and Brian A Coffman

Received: 20 September 2021 Accepted: 8 December 2021 Published: 10 December 2021

Publisher's Note: MDPI stays neutral with regard to jurisdictional claims in published maps and institutional affiliations.

Copyright: (C) 2021 by the authors Licensee MDPI, Basel, Switzerland. This article is an open access article distributed under the terms and conditions of the Creative Commons Attribution (CC BY) license (https:/ / creativecommons.org/licenses/by/ $4.0 /)$.
* Correspondence: armida.mucci@unicampania.it; Tel.: +39-081-5665153

$+\quad$ These authors contributed equally to the paper.

$\ddagger \quad$ The members of the Italian Network for Research on Psychoses involved in the add-on EEG study are listed in the Acknowledgments.

Abstract: Neurocognitive deficits and negative symptoms (NS) have a pivotal role in subjects with schizophrenia (SCZ) due to their impact on patients' functioning in everyday life and their influence on goal-directed behavior and decision-making. P3b is considered an optimal electrophysiological candidate biomarker of neurocognitive impairment for its association with the allocation of attentional resources to task-relevant stimuli, an important factor for efficient decision-making, as well as for motivation-related processes. Furthermore, associations between P3b deficits and NS have been reported. The current research aims to fill the lack of studies investigating, in the same subjects, the associations of $\mathrm{P} 3 \mathrm{~b}$ with multiple cognitive domains and the expressive and motivation-related domains of NS, evaluated with state-of-the-art instruments. One hundred and fourteen SCZ and 63 healthy controls (HCs) were included in the study. P3b amplitude was significantly reduced and P3b latency prolonged in SCZ as compared to HCs. In SCZ, a positive correlation was found between P3b latency and age and between P3b amplitude and the Attention-vigilance domain, while no significant correlations were found between P3b and the two NS domains. Our results indicate that the effortful allocation of attention to task-relevant stimuli, an important component of decision-making, is compromised in SCZ, independently of motivation deficits or other NS.

Keywords: schizophrenia; neurocognition; negative symptoms; EEG; P3b

\section{Introduction}

Neurocognitive deficits and negative symptoms have a pivotal role in schizophrenia due to their severe impact on patients' functioning in daily life and the absence of effective pharmacological treatments targeting them [1-14].

A mild to severe impairment in neurocognitive skills is present in the majority of subjects with schizophrenia, independently of the severity of symptoms. Furthermore, this impairment can be detected throughout different phases of schizophrenia, such as the premorbid, prodromal and remission stages of the illness or even in non-affected 
relatives of subjects with schizophrenia [15-27]. This deficit affects several neurocognitive domains, such as attention, speed of processing, working memory, visuospatial learning and memory, verbal learning and memory, reasoning, problem solving and executive functions (e.g., the ability to plan, execute and monitor goal-directed behavior in a flexible and adaptive way) $[8,28,29]$. From a neurobiological perspective, impairments in these functions might be explained as the cumulative effect of abnormalities in processes such as early neurodevelopment, neuronal maturation and neuroplasticity, thus leading to faulty cortico-cerebellar-thalamic-cortical circuits [30-36].

As regard to negative symptoms, according to the current conceptualization, they include blunted affect (reduced intensity and range of emotional expression), alogia (reduced spontaneous speech and loss of conversational fluency), avolition (reduced interest and motivation for goal-directed activities), asociality (diminished social drive or interest and desire for affiliation) and anhedonia (reduced ability to experience or anticipate pleasure) [37-40]. These symptoms cluster into two domains, the Expressive one, which includes blunted affect and alogia, and the Experiential domain, which includes avolition, anhedonia and asociality $[38,40-45]$. The most updated hypothesis underlying negative symptoms indicates a relationship between the Experiential domain and deficits in different aspects of motivation, which are fundamental for the achievement of goal-directed decision-making $[40,42,46-68]$. These compromized aspects include abnormalities in reward prediction (the ability to predict a pleasant experience), value encoding (the ability to determine current value of a stimulus in the context of a motivational state), action outcome contingency learning (the ability to know the causal consequences of an action) and in the integration of goal-directed behavior and experienced value [40,61-63,69-71]. Motivational deficits might also be due to abnormalities in orientation towards salient stimuli (aversive or rewarding stimuli), cognitive activation and general motivation [40,69,70,72]. Another hypothesis states that Experiential domain symptoms, in particular avolition, are actually caused by deficits in the executive control of behavior. Indeed, it has been demonstrated that deficits in plan elaboration might impair goal-directed behaviour, with subsequent reduced motivation and increased negative symptoms of the experiential type, i.e., avolition, anhedonia and asociality $[40,65,73,74]$. However, findings across studies are inconsistent and need further investigation $[40,65,73-76]$.

Intuitively, deficits in different aspects of motivation and neurocognitive skills, for instance in executive functions and in the allocation of attentional resources to relevant stimuli, might hinder decision making and goal-directed behavior [77,78]. However, it is not clear whether these processes share common pathophysiological mechanisms or whether they affect goal-directed decisions through different neuronal pathways. Furthermore, studies using reward-related tasks do not discriminate between different aspects of decision-making deficits: those related to the allocation of resources to task-relevant stimuli, which do not involve motivational deficits, and those deriving from impaired reward processing, including valuation, learning of reward-outcome associations, which also can impair decision making.

In the context of schizophrenia research, electrophysiological (EEG) recordings have repeatedly been employed to investigate the neurobiological correlates of cognitive impairment and negative symptoms $[79,80]$. Specifically, the analysis of event-related potentials (ERPs) represents an objective tool to decipher mental processes, due to its high temporal resolution in capturing responses to internal and external events $[81,82]$.

One of the ERPs most extensively studied is P300, a positive-going deflection peaking between 270 and $600 \mathrm{msec}$, which can be identified following the presentation of infrequent auditory, visual or somatosensory stimuli $[83,84]$. In addition, P300 can be recorded using experimental paradigms focusing on decision-making and risk evaluation [85], motivation and anticipation of reward [86-89], perception of emotions [90,91] and allocation of attentional resources [92]. Different subcomponents of P300 have been categorized, which present distinct neural generator sources, topographic maps and peak latencies depending on the paradigm used [92-94]. Two main subtypes have been characterised: P3a 
and P3b [92]. The former can be recognised for its scalp distribution with a fronto-central maximum and its elicitation in response to deviant and unexpected events, regardless of their task-relevance. It is therefore often been categorised as a marker of saliency and unconscious attentional capture [92]. Conversely, P3b has a more parietal distribution and is linked to sensory processing of a rare stimulus that is task-relevant, i.e., requiring subject's response.

In psychiatric research, P300 started to gain attention due to the consistent alterations recorded in subjects with schizophrenia. In fact, numerous studies have reported a reduction in P300 amplitude and delayed latency of its peak both in subjects with chronic schizophrenia [95-97] and in subjects at prodromal and early stages of the illness [98].

Furthermore, P3b has been regarded as a candidate biomarker of neurocognitive impairment, due to its linkage in physiological conditions to vigilance, allocation of attentional resources, direct updating of the stimulus representation and executive functions [83]. In addition, it has also been observed that increasing age is associated with alterations of P3b probably due to cognitive decline linked to aging [99-101].

Previous studies in schizophrenia have observed a direct association between deficits in the elicitation of P3b and the severity of impairments in attention [102-105], executive functions [102,106,107], memory [105,107-112] and verbal learning [112-114]. However, other studies did not report any correlations between P3b amplitude and neurocognitive impairment in subjects with schizophrenia [113,115-117]. These inconsistent findings might be due to differences across studies in sample sizes, characteristics of included patients, as well as in instruments used to assess neurocognitive impairment.

In addition, some studies found that reductions in P3b amplitude were correlated to negative symptoms severity in subjects with chronic schizophrenia [118-120] and in subjects at-risk for psychosis [121-123]. One study reported a relationship between the improvement in negative symptom severity scores and the increase of P300 amplitude following antipsychotic medications [124]. Conversely, some studies did not report any associations between P3b and negative symptoms [88,125-127]. In the study of Vignapiano et al. [88], the authors found that P300 amplitude for large reward and large loss was inversely related to trait anhedonia.

It is important to point out that the majority of the above-mentioned studies [118,119,123-126] evaluated negative symptoms using first generation rating scales, such as the Positive and Negative Syndrome Scale [128], the Scale for the Assessment of Negative Symptoms (SANS) [129] and the Brief Psychiatric Rating Scale (BPRS) [130]. However, these scales present some limitations, as they include aspects that actually are not conceptualized as negative symptoms, but are mostly related to cognitive functions and disorganization [38].

The association between P300 abnormalities with clinical and cognitive aspects in subjects with schizophrenia is still a matter of debate due to the inconsistent findings reported in the literature.

Our study aims to investigate in a large sample of subjects with schizophrenia the associations of $\mathrm{P} 3 \mathrm{~b}$ with multiple cognitive domains and the expressive and motivationrelated domains of NS, evaluated with state-of-the-art instruments.

To pursuit this aim, the study investigated: (1) the differences in P3b parameters between subjects with schizophrenia and healthy controls; (2) the associations between P3b parameters with neurocognitive functions both in patients and healthy controls; (3) the relationship between $\mathrm{P} 3 \mathrm{~b}$ parameters and negative symptoms in subjects with schizophrenia.

\section{Materials and Methods}

\subsection{Study Participants}

The study has been conducted as part of the add-on EEG study of the Italian Network for Research on Psychoses [2]. One hundred and forty-eight subjects with schizophrenia (SCZ) and 70 healthy controls (HCs) were recruited for the study, at five research sites in Naples, Foggia, Rome Tor Vergata, Rome "Sapienza" and Salerno. The SCZ sample 
included individuals seen at the outpatient units of the five mentioned Italian university psychiatric clinics. All patients had a diagnosis of schizophrenia according to DSM-IV, confirmed with the Structured Clinical Interview for DSM IV-Patient version (SCID-I-P), and an age between 18 and 65 years.

The HCs sample was recruited from the community at the same sites mentioned above. Inclusion criteria for HCs were the absence of a current or lifetime Axis I or II psychiatric diagnosis. Exclusion criteria for both groups were: (a) a history of head trauma with loss of consciousness; (b) a history of moderate to severe mental retardation or of neurological diseases; (c) a history of alcohol and/or substance abuse in the last six months; (d) current pregnancy or lactation; and (e) inability to provide an informed consent. SCZ with treatment modifications and/or hospitalization due to symptom exacerbation in the last three months were excluded.

The Ethics Committee of the involved institutions approved the electrophysiological add-on study. The study has been performed in accordance with the ethical standards laid down in the 1964 Declaration of Helsinki. All participants signed a written informed consent to participate after receiving a detailed explanation of the study procedures and goals.

\subsection{Clinical and Neurocognitive Assessments}

All subjects recruited were evaluated for sociodemographic variables such as age, education and gender, through a clinical form filled using every available source of information.

For SCZ, a semi-structured interview, the Brief Negative Symptom Scale (BNSS) was used to assess negative symptoms [131,132]. The scale includes 13 items, organized into six subscales (Blunted Affect, Alogia, Avolition, Anhedonia, Asociality and a control subscale named Distress). All the items use a seven-point (0-6) scale, thus ranging from absent $(0)$ to moderate (3) to extremely severe (6) symptoms (except Distress for which the severity rating is reversed: 0 normal distress and 6 absent).

With regard to the two domains, the Experiential domain was computed by summing the scores on the subscales Anhedonia (consummatory and anticipatory anhedonia), Avolition and Asociality; the Expressive deficit was computed by summing the scores on the subscales Blunted Affect and Alogia [131].

The Positive and Negative Syndrome Scale (PANSS) was used to rate the severity of positive symptoms and disorganization [128]. All items are rated on a seven-point scale from 1 to 7 , ranging from absent (1) to moderate (4) to extremely severe (7). We also assessed depressive symptoms using the Calgary Depression Scale for Schizophrenia (CDSS) [133] and extrapyramidal symptoms using the St. Hans Rating Scale (SHRS) [134].

Neurocognitive domains were assessed in SCZ and HCs using the Measurement and Treatment Research to Improve Cognition in Schizophrenia (MATRICS) Consensus Cognitive Battery (MCCB) [135]. This battery includes tests for the assessment of distinct neurocognitive domains: speed of processing, attention/vigilance, working memory, verbal learning and memory, visuospatial learning and memory, reasoning and problem solving.

Raw scores on the MCCB were then standardized to T-scores, corrected for age and gender, based on the Italian normative sample of community participants.

\subsection{EEG Recording Procedure}

EEGs were recorded using two highly comparable EEG recording systems: EASYS2 (Brainscope, Prague) and Galileo MIZAR-sirius (EBNeuro, Florence). Before starting the study, a harmonization of the amplifier settings and recording procedure was carried out to ensure the same settings in all the centers. All EEGs were recorded using a cap electrode system with 29 unipolar leads (Fpz, Fz, Cz, Pz, Oz, F3, F4, C3, C4, FC5, FC6, P3, P4, O1, O2, Fp1, Fp2, F7, F8, T3, T4, T5, T6, AF3, AF4, PO7, PO8, Right Mastoid and Left Mastoid), which were placed following the 10-20 system. All the leads were referenced to the linked earlobes (a resistor of $10 \mathrm{k} \Omega$ was interposed between the earlobe leads). A ground electrode was placed on the forehead. 
For artifact monitoring, a horizontal electro-oculogram (hEOG) was recorded from the epicanthus of each eye, and a vertical EOG (vEOG) from the leads beneath and above the right eye. All impedances of the leads were kept below $5 \mathrm{k} \Omega$. The EEG data were filtered with a band-pass of $0.15-70 \mathrm{~Hz}$ and recorded with a sampling rate of $512 \mathrm{~Hz}$.

A calibration was performed for all channels, using a $50 \mu \mathrm{V}$ sine wave, before each recording session. Subjects were seated in a reclining chair, in a sound attenuated room, minimizing eye movement or muscle tension. Subjects performed an auditory "odd-ball" task during which 320 standard stimuli $(1500-\mathrm{Hz}, 80 \mathrm{~dB})$ and 80 target stimuli, deviant for their frequency $(1000-\mathrm{Hz}, 80 \mathrm{~dB})$, were played. Patient were asked to press the button as fast as possible upon the appearance of every target stimulus. Participants who scored less than $60 \%$ on the behavioral target detection task were excluded from the analysis.

Participants were instructed not to drink coffee or tea and to abstain from smoking cigarettes in the $2 \mathrm{~h}$ before the beginning of the recording session and did not take psychotropic medications in the morning. Information on the quality of sleep during the night prior to the recording was collected and the EEG session was postponed if the subject reported a non-restoring sleep.

\subsection{EEG Data Preprocessing}

One expert from the coordinating center (Naples) using Brain Vision Analyzer software (Brain Products, Munich, Germany) performed all the pre-processing analyses on data collected by the different recording sites. In order to characterize P3b deflections, we considered only the 80 trials when target stimuli were played. Data were parsed into epochs of 1000 ms duration, which were time-locked to the onset of the cue and spanned from a $100 \mathrm{~ms}$ pre-stimulus period up to $900 \mathrm{msec}$ post-stimulus. The recorded EEG was digitally filtered offline using a band-pass filter of $0.01-30 \mathrm{~Hz}$. P3b waves were extracted in each subject by the averaging method on all the "target" trials, in order to improve the signal/noise ratio, ruling out baseline activity not related to the stimulus. Trials with drifts larger than $\pm 100 \mu \mathrm{V}$ in any scalp electrode were rejected. If following artifacts and noisy trials removal, less than 40 usable target trials (50\% of target trials) remained, the subject was excluded from the analysis. Data were baseline-corrected using the $100 \mathrm{~ms}$ time window preceding stimuli. P3b peaks were automatically marked using the "peak finder" function of Brain Analyzer, as the most positive point ranging from 240 to $480 \mathrm{~ms}$. Due to its prevalent parietal localization, we analyzed only amplitude and latency of P3b from the Pz electrode $[105,136]$.

\subsection{Statistical Analysis}

All statistical analyses were computed using SPSS Version 22.0 (Armonk, NY, USA: IBM Corporation, 2014). Normality tests were performed on demographic, clinical and electrophysiological variables to test distribution of data in order to set up parametric or non-parametric tests.

Two sample $t$-tests, Mann-Whitney U Tests and $\chi^{2}$ tests were used to compare SCZ and HCs on demographic characteristics, MCCB scores and amplitude and latency of P3b, based on normality test results. Spearman's rank correlations were performed to test the relationships between $\mathrm{P} 3 \mathrm{~b}$ parameters with age, neurocognitive domains (separately for the two sample groups) and the two negative symptom domains in SCZ. For all the correlations considered, Bonferroni-Holm correction was applied in order to control for type-I error inflation. Furthermore, we performed partial correlations to exclude the influence of other variables (for negative symptoms we decided to control the effect of age, positive symptoms, disorganization, depression and parkinsonism; for neurocognitive impairment the effect of age and education). 


\section{Results}

\subsection{Participants Included}

One hundred and forty-eight SCZ and 70 HCs were originally enrolled as part of the add-on EEG study. However, 23 SCZ and 4 HCs did not complete the paradigm for P3b recording. Furthermore, 11 SCZ and $3 \mathrm{HC}$ sere excluded either for the high presence of artefacts in the ERP recordings or for low behavioural performance on the active target recognition task. Thus, the final study sample consisted of 114 SCZ and 63 HCs.

\subsection{Demographic Characteristics, Neurocognitive Functions and Illness Related Variables}

Data on relevant demographic characteristics, neurocognitive functions and illness related variables are provided in Table 1 . Gender distribution was significantly different between the two groups $\left(\chi^{2}=7.214 ; p<0.01\right)$ since in the SCZ group the number of male subjects was higher, as compared to HCs. There was no significant difference in the mean age between the two sample groups $(\mathrm{U}=2982.00 ; p>0.05)$. Furthermore, not unexpectedly, SCZ had significantly lower education as compared to HCs $(p<0.01)$. The mean of MCCB domain scores are shown in Table 1 . The two groups significantly differed for the scores recorded on all six neurocognitive domains $(p<0.0001)$, with SCZ showing a noticeable worse performance on all the evaluated domains.

Table 1. Demographic characteristics, neurocognitive functions and illness related variables.

\begin{tabular}{|c|c|c|c|c|}
\hline \multirow{3}{*}{ Gender } & \multirow{3}{*}{$\begin{array}{c}\text { SCZ }(n=114) \\
81 \mathrm{M}-33 \mathrm{~W} \\
\text { Mean } \pm \text { SD }\end{array}$} & \multirow{3}{*}{$\begin{array}{c}\text { HCs }(n=63) \\
32 \mathrm{M}-31 \mathrm{~W} \\
\text { Mean } \pm \text { SD }\end{array}$} & \multicolumn{2}{|c|}{ Statistics } \\
\hline & & & \multicolumn{2}{|c|}{$\chi^{2}=7.214 ; p=0.007$} \\
\hline & & & $t / \mathrm{U}$ & $p$ \\
\hline Age & $36.86 \pm 9.39$ & $34.44 \pm 12.48$ & $\mathrm{U}=2982.00$ & 0.062 \\
\hline Educational level (years) & $12.35 \pm 3.02$ & $13.98 \pm 4.04$ & $\mathrm{U}=2759.00$ & 0.0083 \\
\hline BNSS Expressive Deficit Domain & $11.35 \pm 7.27$ & - & - & - \\
\hline BNSS Experiential Domain & $21.11 \pm 9.25$ & - & - & - \\
\hline PANSS Positive & $8.33 \pm 4.74$ & - & - & - \\
\hline PANSS Disorganization & $8.60 \pm 3.49$ & - & - & - \\
\hline CDSS Total score & $3.24 \pm 3.92$ & - & - & - \\
\hline SHRS Global Parkinsonism & $0.86 \pm 1.15$ & - & - & - \\
\hline MCCB SoP & $32.79 \pm 10.42$ & $48.79 \pm 9.94$ & $t=-9.774$ & $<0.0001$ \\
\hline MCCB AV & $40.20 \pm 10.27$ & $51.67 \pm 10.22$ & $t=-6.420$ & $<0.0001$ \\
\hline MCCB WM & $36.33 \pm 11.78$ & $50.60 \pm 10.12$ & $t=-7.189$ & $<0.0001$ \\
\hline MCCB VrbLrn & $37.02 \pm 11.03$ & $52.13 \pm 7.30$ & $t=-10.489$ & $<0.0001$ \\
\hline MCCB VisLrn & $31.86 \pm 13.20$ & $47.76 \pm 11.19$ & $\mathrm{U}=1033.50$ & $<0.0001$ \\
\hline MCCB RPS & $38.53 \pm 11.33$ & $51.03 \pm 8.75$ & $\mathrm{U}=1262.00$ & $<0.0001$ \\
\hline
\end{tabular}

AV: Attention vigilance; BNSS: Brief Negative Symptom Scale; CDSS: The Calgary Depression Scale for Schizophrenia; HCs: Healthy controls; MCCB: MATRICS Consensus Cognitive Battery; PANSS: Positive and Negative Syndrome Scale; RPS: Reasoning and Problem Solving; SCZ: subjects with schizophrenia; SD: Standard Deviation; SHRS: The St. Hans Rating Scale for extrapyramidal syndrome; SoP: Speed of processing; VisLrn: Visuo-spatial learning and memory; VrbLrn: Verbal Learning and memory; WM: working memory. $p$ values in bold indicate statistical significance.

\subsection{Group Comparison on P3b Amplitude and Latency}

SCZ showed reduced P3b amplitude and delayed latency as compared to HCs (Figure 1). 


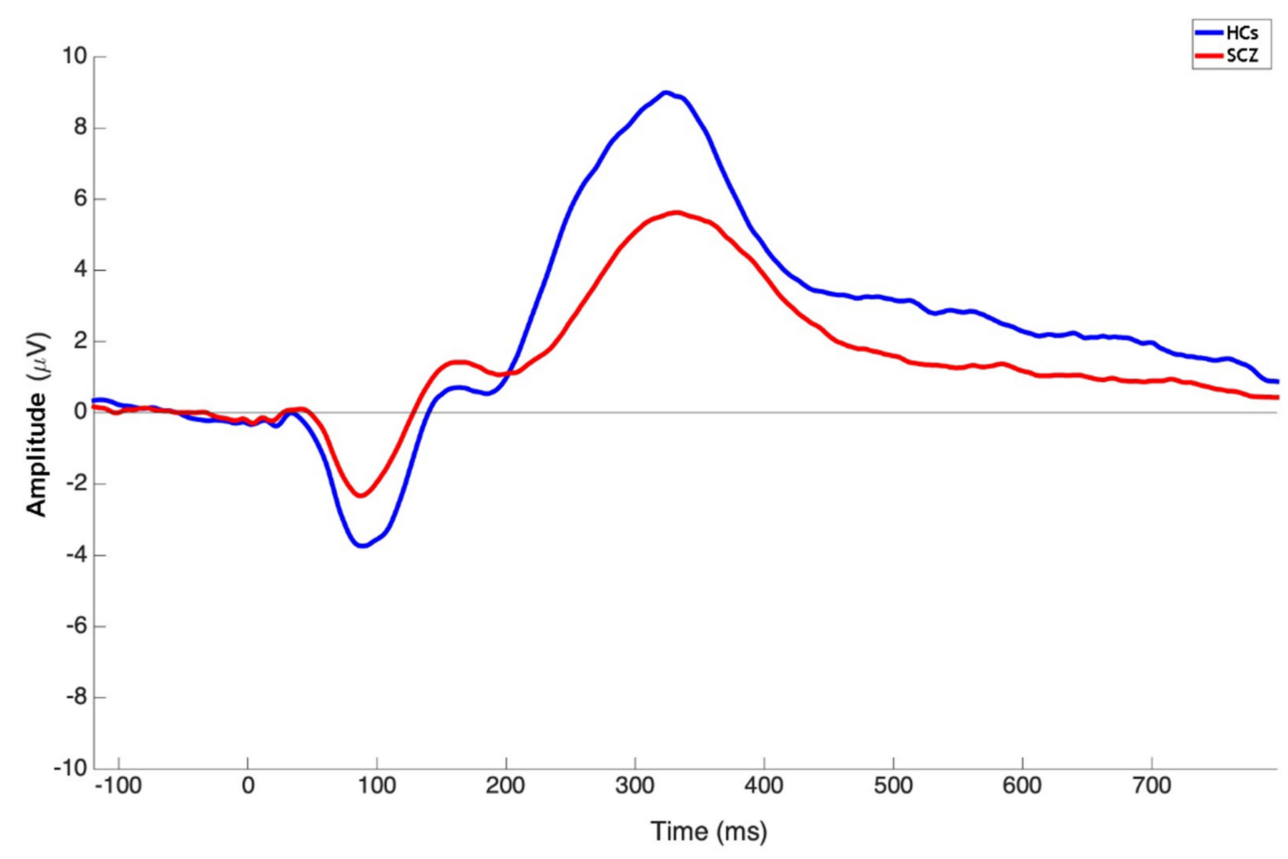

Figure 1. Grand average ERP waveforms of subjects with schizophrenia (red line) and healthy controls (blue line) from the Pz electrode.

Mann-Whitney $\mathrm{U}$ tests showed that there was a significant difference in $\mathrm{P} 3 \mathrm{~b}$ amplitude $(\mathrm{U}=2023.00 ; p<0.0001)$ and latency $(\mathrm{U}=2683.50 ; p=0.0054)$ between $\mathrm{SCZ}$ and HCs as recorded at $\mathrm{Pz}$ (Table 2).

Table 2. Comparison between SCZ and HCs of P3b amplitude and latency.

\begin{tabular}{|c|c|c|c|c|}
\hline & SCZ & HCs & & \\
\hline & Mean \pm SD & Mean \pm SD & $\mathbf{U}$ & $p$ \\
\hline P3b Pz Amplitude & $9.60 \pm 5.09$ & $14.05 \pm 6.10$ & 2023.00 & $<0.0001$ \\
\hline P3b Pz Latency & $347.36 \pm 44.83$ & $327.26 \pm 33.25$ & 2683.50 & 0.0054 \\
\hline
\end{tabular}

HCs: Healthy controls; SCZ: subjects with schizophrenia; SD: Standard Deviation. $p$ values in bold indicate statistical significance.

\subsection{Correlation Analyses}

Considering neurocognitive functioning, a significant correlation was found in SCZ between P3b amplitude and the attention-vigilance domain scores $\left(r_{\mathrm{s}}=0.259 ; p=0.0076\right)$, which remained significant even when controlling for age and years of education (Table 3; Figure 2). Furthermore, a negative correlation was observed at trend level between P3b latency and verbal $\left(r_{\mathrm{s}}=-0.223 ; p=0.019\right)$ and visuo-spatial learning and memory $\left(r_{\mathrm{S}}=-0.195 ; p=0.043\right)$, which did not survive correction for multiple tests (Table 3$)$. In SCZ, a significant positive correlation was found between P3b latency and age $\left(r_{\mathrm{S}}=0.320\right.$; $p=0.00052)$ (Table 3). No significant correlations $(p>0.05)$ were found between P3b amplitude or latency and the two negative symptom domains. 
Table 3. Correlations between P3b and clinical/cognitive variables in SCZ.

\begin{tabular}{|c|c|c|c|c|c|c|c|c|c|c|}
\hline & & SoP & AV & WM & VrbLrn & VisLrn & RPS & Age & ED & Exp \\
\hline \multirow[t]{2}{*}{$\begin{array}{c}\text { P3b Pz } \\
\text { Amplitude }\end{array}$} & $\begin{array}{c}\text { Spearman's } \\
\text { correlation } \\
\text { coefficient }\end{array}$ & 0.140 & 0.259 & 0.114 & 0.148 & 0.044 & 0.067 & -0.0170 & -0.060 & -0.053 \\
\hline & $p$ value & 0.144 & $0.0076^{*}$ & 0.238 & 0.124 & 0.650 & 0.490 & 0.070 & 0.533 & 0.577 \\
\hline \multirow[t]{2}{*}{ P3b Pz Latency } & $\begin{array}{c}\text { Spearman's } \\
\text { correlation } \\
\text { coefficient }\end{array}$ & -0.027 & -0.107 & -0.119 & -0.223 & -0.195 & -0.093 & 0.320 & -0.083 & -0.037 \\
\hline & $p$ value & 0.783 & 0.278 & 0.216 & 0.019 & 0.043 & 0.338 & 0.00052 & 0.387 & 0.701 \\
\hline
\end{tabular}

SoP: Speed of processing; AV: Attention vigilance; WM: working memory; VrbLrn: Verbal Learning and memory; VisLrn: Visuo-spatial learning and memory; RPS: Reasoning and Problem Solving; ED: Expressive deficit Domain; Exp: Experiential Domain. Significant $p$ value thresholds for correlations: neurocognitive domains $(p<0.0083)$; age $(0.05) ; 2$ domains of negative symptoms $(p<0.025) .{ }^{*}$ The correlation remained significant when controlling for age and years of education.

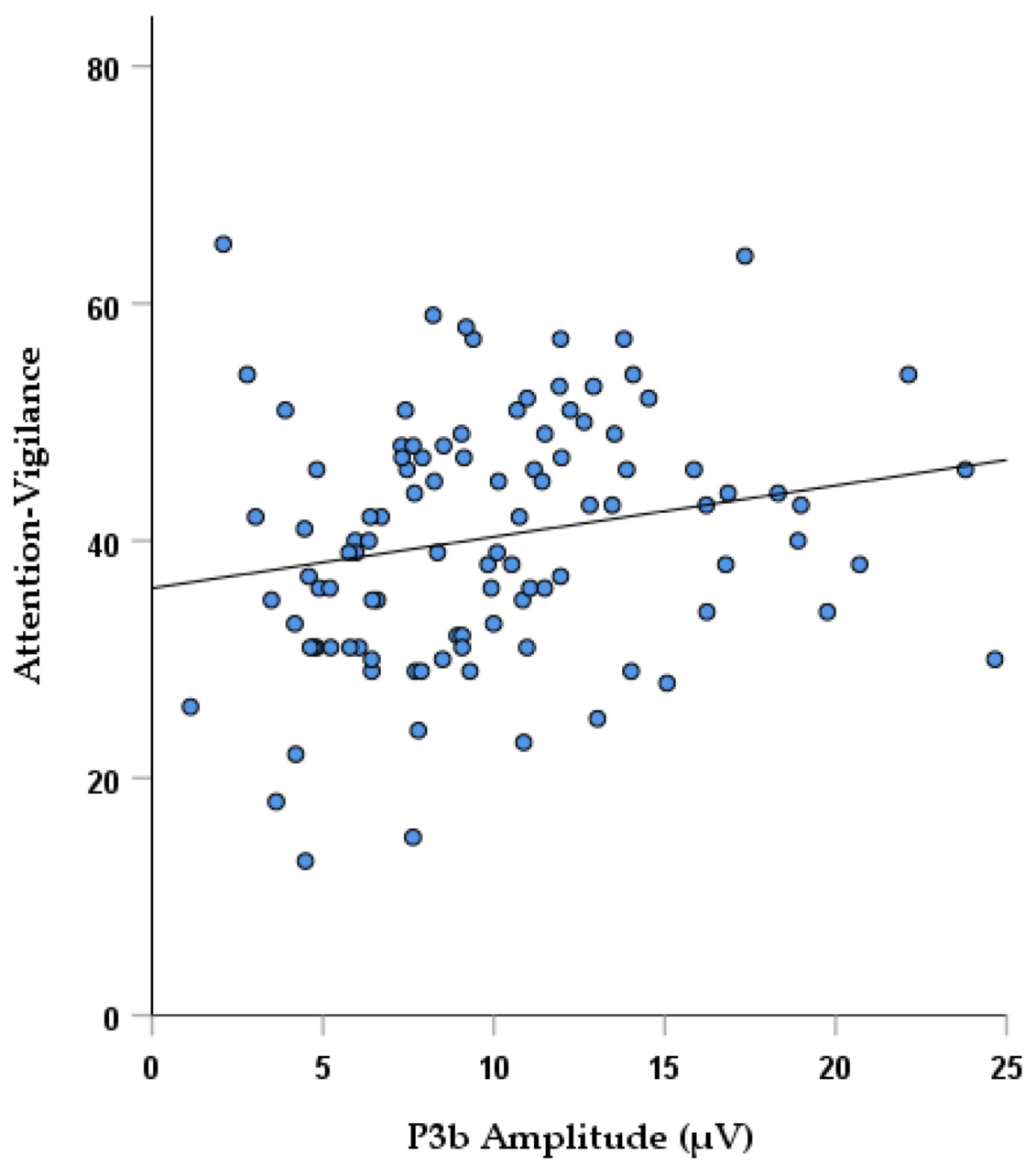

Figure 2. Correlation between P3b amplitude and attention-vigilance domain scores in SCZ.

In HCs, neither of the two P3b parameters was associated with the six cognitive domains considered. However, age was negatively correlated with P3b amplitude $\left(r_{\mathrm{S}}=-0.470\right.$; $p=0.00010)$, and positively with P3b latency $\left(r_{\mathrm{s}}=-0.309 ; p=0.014\right)$ (Table 4$)$. 
Table 4. Correlations between P3b, age and cognitive variables in HCs.

\begin{tabular}{cccccccccc}
\hline & & SoP & AV & WM & VrbLrn & VisLrn & RPS & Age \\
\hline \multirow{2}{*}{ P3b Pz Amplitude } & $\begin{array}{c}\text { Spearman's correlation } \\
\text { coefficient }\end{array}$ & -0.028 & 0.151 & 0.042 & -0.086 & -0.017 & 0.064 & -0.470 \\
\cline { 2 - 8 } & $p$ value & 0.827 & 0.305 & 0.757 & 0.532 & 0.904 & 0.633 & $\mathbf{0 . 0 0 0 1 0}$ \\
\hline \multirow{2}{*}{ P3b Pz Latency } & $\begin{array}{c}\text { Spearman's correlation } \\
\text { coefficient }\end{array}$ & 0.030 & 0.021 & -0.154 & -0.154 & -0.159 & -0.067 & 0.309 \\
\cline { 2 - 8 } & $p$ value & 0.819 & 0.886 & 0.249 & 0.262 & 0.266 & 0.620 & $\mathbf{0 . 0 1 4}$ \\
\hline
\end{tabular}

SoP: Speed of processing; AV: Attention-vigilance; WM: working memory; VrbLrn: Verbal Learning and memory; VisLrn: Visuo-spatial learning and memory; RPS: Reasoning and Problem Solving. Significant $p$ value thresholds for correlations: neurocognitive domains $(p<0.0083)$; age (0.05). $p$ values in bold indicate statistical significance.

\subsection{Control Analyses}

Additional control tests were performed. Firstly, regression models were designed to check if P3b amplitude/latency could predict neurocognition scores controlling for group, education and age (Supplementary Material). Multiple regression models showed that T-Scores for two neurocognitive domains could be predicted from P3b values. Specifically, Attention-vigilance domain scores $\left(R^{2}=0.256, p<0.001\right)$ could be predicted from group, education and P3b amplitude, while Visual $\left(R^{2}=0.167, p<0.001\right)$ learning scores were predicted by group and P3b latency. Furthermore, in both regression models no significant interaction effects $(p>0.05)$ were detected between the electrophysiological features and the other significant predictors. Secondly, in order to remove the effects of normal aging, while allowing disorder-relevant aging effects to remain, additional correlation tests employing age-corrected P3b amplitude and latency z-scores were performed (Supplementary Tables S1 and S2). Results showed that the significant correlation between P3b amplitude and Attention-vigilance was still detectable in SCZ as well as a weaker, but still significant, negative correlation was recorded between P3b latency and Verbal Learning scores (Supplementary Table S1). Furthermore, also in these control correlation analyses, no significant correlations emerged with negative symptom domains. Finally, we also tested if P3b values in SCZ could be possibly related to depression (CDSS Total scores) (Supplementary Material), but no significant correlation emerged $(p>0.05)$.

\section{Discussion}

The current study aimed to examine auditory-elicited P3b in schizophrenia, disentangling its association with neurocognitive impairment and negative symptoms. Three main objectives were addressed through data analysis: (1) To identify differences in P3b amplitude and peak latency between subjects with schizophrenia and healthy controls; (2) to investigate the presence of associations between P3b parameters with neurocognitive domains in subjects with schizophrenia and healthy controls; and (3) to detect correlations between P3b characteristics and severity of the two domains of negative symptoms in subjects with schizophrenia.

The outcomes of the analysis revealed a reduction in P3b amplitude and a delayed peak in response to target stimuli in subjects with schizophrenia as compared to healthy controls. From the correlation analysis, a statistically significant association between diminished P3b amplitude and lower scores in the attention-vigilance domain was found in subjects with schizophrenia. Additionally, in the same subjects a trend-level association was reported between P3b latency and verbal and visual learning. No significant relationship emerged in healthy controls between $\mathrm{P} 3 \mathrm{~b}$ parameters and cognitive functions, probably due to the existence of a marked cognitive impairment present only in subjects with schizophrenia. Nonetheless, the control analysis using multiple regression models, which combined the two sample groups, revealed that for the Attention-vigilance and visual learning T-scores, lower amplitude and delayed latency in P3b were related to worse cognitive performance, in the whole study sample. This suggest that the slopes of the equations predicting 
Attention-vigilance and Visual learning scores from P3b values were not significantly different between the two groups. However, the lack of significant associations in the main correlation analysis between P3b and neurocognitive domains in healthy subjects might be due to two factors. One possible explanation might be that the lower number of subjects included in the HCs group has hindered the emergence of significant correlations. Secondly, the majority of the T-scores values for this group were distributed only in the medium-high range of the values spectrum, which might lead to the absence of a robust correlation between P3b and cognitive performance. This reinforces the hypothesis that the association between P3b features and neurocognition might be present and detectable mainly in pathological conditions.

Furthermore, as regard to the possible association between P3b and age, we found in both sample groups that $\mathrm{P} 3 \mathrm{~b}$ peak latency was proportionally delayed as age increased. A statistically significant relationship between P3b amplitude reductions and increasing age was found in healthy subjects, while an association at trend-level was found in subjects with schizophrenia. Furthermore, the control analyses have also reinforced the finding that the strong association of $\mathrm{P} 3 \mathrm{~b}$ attenuation with aging was not driving the correlation with attentive impairment present in subjects with schizophrenia. Finally, no associations between negative symptom domains and P3b measures emerged in subjects with schizophrenia in the main and control analyses.

Our findings of altered P3b values in patients, displayed as reduced amplitude and delayed latency, are in agreement with the vast literature produced on this EEG-based measure in schizophrenia $[96,97]$. Previous studies have highlighted that dysfunctions in the P3b elicitation in schizophrenia might arise from hypo-activation of various brain regions including temporal areas, the cingulate cortex and prefrontal and frontal structures $[127,137-140]$.

However, despite the vast literature focusing on P3b abnormalities in schizophrenia, findings from previous studies do not allow conclusions on whether these electrophysiological alterations relate to cognitive and/or clinical features of schizophrenia. Our current study revealed that in a large sample of stabilized subjects with chronic schizophrenia, lower P3b amplitude reflected worse performance in the attention-vigilance test scores, reinforcing the hypothesis that $\mathrm{P} 3 \mathrm{~b}$ is an electrophysiological index of allocation of attentional resources $[92,105,141]$. The strength of this finding stems from fact that EEG indices were analyzed in a large sample of patients; cognitive functions were evaluated with the MCCB, which is regarded as the gold standard in assessing cognitive impairment in subjects with schizophrenia, and that this outcome was specific of cognitive impairment and not negative symptoms, as documented by the absence of association between P3b and negative symptoms, assessed with a second-generation rating scale [38]. Most of the previous studies have reported a similar linkage between P3b alterations and lower attentive capacities in subjects affected by schizophrenia [102-105,141]. These data seem to highlight that diminished P3b amplitude values signal an impairment in orientation to task-relevant target information leading to even higher-order deficits in executive processing observed in pathological conditions.

Neuroimaging studies seem to point to a series of alterations in the brain architecture as the possible origin of the attention impairment observed in schizophrenia [142-144]. Specifically, disruptions in temporal areas and fronto-limbic circuitry, critical for maintaining an effective interaction between frontal executive and limbic affective processing networks, have been linked to attention deficits $[145,146]$. Areas involved in these networks, have also been classified as some of the neural generators of P3b, reinforcing the hypothesized link between P3b dysfunctions and alterations in attention circuits [147-149].

We also reported a significant association between P3b and aging both in subjects with schizophrenia and healthy controls. This is in accordance with previous results that found a progressive deterioration in P3b elicitation, suggesting that the progressive neural decline observed in aging is likely to deteriorate the neuronal substrates underpinning P3b [101,150-152]. The delayed P3b peaks observed in older subjects has been interpreted 
as an index of slower processing speed, while lower amplitude might reflect the diminished availability of cognitive resources for a given task [99]. Therefore, studies have tried to understand whether changes in P3b only reflect the process of aging or whether these could be used as markers of cognitive decline. One study by Porcaro et al. seems to signal that lower P3b amplitude values were reflecting cognitive impairment, independently from the influence of aging [101]. Our study seems to reinforce this hypothesis, since the correlation found in schizophrenia between P3b and attention remained significant even when controlling for age. Furthermore, an important factor to consider is that in our sample no significant relationships were traced between $\mathrm{P} 3 \mathrm{~b}$ characteristics and neurocognitive domains in healthy subjects, which individually showed close to normative T-scores, with no sign of cognitive impairment. The presence of the correlation only in the pathological condition, supports the hypothesis that P3b could be used as a marker of severity of neurocognitive impairments, independently from aging [105].

With regard to negative symptoms, we did not find any significant correlations between either the expressive or experiential domain and P3b parameters. In this case, the current literature presents contrasting results. Indeed, some studies reported an association between negative symptoms and P3b amplitude in subjects with chronic schizophrenia [118-120] and subjects at-risk for psychosis [121-123]. Studies that employed LORETA analysis found that negative symptoms were related to P300 current density localized in the left temporal areas [138,153], posterior cingulate [138] and precuneus [138]. Conversely, no significant correlations were recorded in other studies [88,125-127]. The differences reported in the current literature might be due to different factors. Firstly, the experimental design could influence the activation of different neuronal circuits, depending for instance on the level of difficulty associated to the task. Furthermore, which negative symptoms are evaluated and which scales are chosen for assessing them might also play a critical role in the variability of the results. In particular, the majority of studies [118-120,123,125,126] used the total score of negative symptoms derived from first generation rating scales, which present several limitations, as they include attentional impairment (SANS, PANSS) or aspects related to disorganization (SANS and PANSS), and provide an inadequate assessment of experiential negative symptoms. Our study aimed to overcome these limitations using the BNSS, a second-generation rating scale, recommended for the assessment of negative symptoms [38].

\section{Conclusions}

In conclusion, in line with previous studies, our results suggested that the elicitation of P3b was noticeably affected in subjects with schizophrenia. These deficits were associated with neurocognitive impairments and not to negative symptoms, suggesting that these two aspects of schizophrenia might not share common pathophysiological mechanisms and could affect higher-order functions, such as goal-directed decision-making, through different mechanisms and neuronal pathways. Further studies, using state-of-the-art instruments, homogenous task design and consistent analysis approaches are recommended in order to confirm the linkage of P3b to severity of neurocognitive impairment in schizophrenia. This would represent a step forward in the search of indices related to those aspects that are recognized as major determinants of poor outcome, such as cognitive impairment, and might therefore foster the development of innovative treatment strategies.

Supplementary Materials: The following are available online at https:/ / www.mdpi.com/article/ 10.3390/brainsci11121632/s1, Table S1: Correlation coefficients of P3 amplitude and latency z-scores with neurocognition and negative symptoms in subjects with schizophrenia, Table S2: Correlation coefficients of P3 amplitude and latency z-scores with neurocognition in healthy controls. 
Author Contributions: Conceptualization, G.M.G., A.P., A.M., G.D.L., M.A., A.B., R.B., G.C., P.G., P.M., C.N., S.G. and M.M.; Methodology, G.M.G., A.P., A.M., G.D.L., M.A., A.B., R.B., G.C., P.G., C.N., S.G. and M.M.; Project administration, A.M., P.M., S.G. and M.M.; Supervision, A.M., S.G. and M.M.; Writing-original draft, G.M.G., A.P., A.M., G.D.L., M.A., A.B., R.B., G.C., P.G., P.M., C.N., S.G. and M.M.; Writing-review and editing, G.M.G., A.P., A.M., G.D.L., M.A., A.B., R.B., G.C., P.G., P.M., C.N., S.G. and M.M. All Authors were responsible for the interpretation of the analyses, contributed to critically revising the content, and approved the final manuscript for submission to Brain Sciences. All authors have read and agreed to the published version of the manuscript.

Funding: The study was funded by the Italian Ministry of Education (grant number: 2010XP2XR4), the Italian Society of Psychopathology (SOPSI), the Italian Society of Biological Psychiatry (SIPB), Roche, Switzerland Lilly, United States AstraZeneca, United Kingdom Lundbeck foundation, Denmark and Bristol-Myers Squibb, United Kingdom. These entities had no role in study design; in the collection, analysis and interpretation of data; in the writing of the report and in the decision to submit the paper for publication.

Institutional Review Board Statement: The study was conducted according to the guidelines of the Declaration of Helsinki, and approved by the Ethics Committee of the involved institutions.

Informed Consent Statement: Informed consent was obtained from all subjects involved in the study.

Data Availability Statement: All data supporting the findings of this study are available within the article.

Acknowledgments: Members of the add-on EEG study of the Italian Network for Research on Psychoses participating in this study include: Francesco Brando, Luigi Giuliani, Eleonora Merlotti, Pasquale Pezzella, Giuseppe Piegari (University of Campania “Luigi Vanvitelli"); Raffaella Carnevale, Maddalena La Montagna (University of Foggia); Fabiola Ferrentino, Alberto Siracusano (University of Rome Tor Vergata); Anna Comparelli, Valentina Corigliano (University of Rome "La Sapienza"); Giammarco Cascino, Gianfranco Del Buono (Department of Mental Health, Salerno).

Conflicts of Interest: The authors declare no conflict of interest.

\section{References}

1. Galderisi, S.; Rucci, P.; Kirkpatrick, B.; Mucci, A.; Gibertoni, D.; Rocca, P.; Rossi, A.; Bertolino, A.; Strauss, G.P.; Aguglia, E.; et al. Interplay Among Psychopathologic Variables, Personal Resources, Context-Related Factors, and Real-life Functioning in Individuals With Schizophrenia: A Network Analysis. JAMA Psychiatry 2018, 75, 396-404. [CrossRef]

2. Galderisi, S.; Rossi, A.; Rocca, P.; Bertolino, A.; Mucci, A.; Bucci, P.; Rucci, P.; Gibertoni, D.; Aguglia, E.; Amore, M.; et al. The influence of illness-related variables, personal resources and context-related factors on real-life functioning of people with schizophrenia. World Psychiatry 2014, 13, 275-287. [CrossRef]

3. Barch, D.M. Nonsocial and social cognitive function in psychosis: Interrelationships, specificity and innovative approaches. World Psychiatry 2019, 18, 117-118. [CrossRef] [PubMed]

4. Galderisi, S.; Rucci, P.; Mucci, A.; Rossi, A.; Rocca, P.; Bertolino, A.; Aguglia, E.; Amore, M.; Bellomo, A.; Bozzatello, P.; et al. The interplay among psychopathology, personal resources, context-related factors and real-life functioning in schizophrenia: Stability in relationships after 4 years and differences in network structure between recovered and non-recovered patients. World Psychiatry 2020, 19, 81-91. [CrossRef] [PubMed]

5. Mucci, A.; Galderisi, S.; Gibertoni, D.; Rossi, A.; Rocca, P.; Bertolino, A.; Aguglia, E.; Amore, M.; Bellomo, A.; Biondi, M.; et al. Factors Associated with Real-Life Functioning in Persons with Schizophrenia in a 4-Year Follow-up Study of the Italian Network for Research on Psychoses. JAMA Psychiatry 2021, 78, 550-559. [CrossRef]

6. Galderisi, S.; Kaiser, S.; Bitter, I.; Nordentoft, M.; Mucci, A.; Sabé, M.; Giordano, G.M.; Nielsen, M.; Glenthøj, L.B.; Pezzella, P.; et al. EPA guidance on treatment of negative symptoms in schizophrenia. Eur. Psychiatry 2021, 64, e21. [CrossRef] [PubMed]

7. Milev, P.; Ho, B.C.; Arndt, S.; Andreasen, N.C. Predictive values of neurocognition and negative symptoms on functional outcome in schizophrenia: A longitudinal first-episode study with 7-year follow-up. Am. J. Psychiatry 2005, 162, 495-506. [CrossRef] [PubMed]

8. Green, M.F.; Horan, W.P.; Lee, J. Nonsocial and social cognition in schizophrenia: Current evidence and future directions. World Psychiatry 2019, 18, 146-161. [CrossRef] [PubMed]

9. Sahakian, B.J.; Savulich, G. Innovative methods for improving cognition, motivation and wellbeing in schizophrenia. World Psychiatry 2019, 18, 168-170. [CrossRef] [PubMed]

10. Falkai, P.; Schmitt, A. The need to develop personalized interventions to improve cognition in schizophrenia. World Psychiatry 2019, 18, 170. [CrossRef] [PubMed]

11. Davidson, M. Cognitive impairment as a diagnostic criterion and treatment target in schizophrenia. World Psychiatry 2019, 18, 171-172. [CrossRef] [PubMed] 
12. Fleischhacker, W.W.; Uchida, H. Critical review of antipsychotic polypharmacy in the treatment of schizophrenia. Int. J. Neuropsychopharmacol. 2014, 17, 1083-1093. [CrossRef]

13. Keefe, R.S.E. Why are there no approved treatments for cognitive impairment in schizophrenia? World Psychiatry 2019, 18, 167-168. [CrossRef]

14. Reichenberg, A.; Velthorst, E.; Davidson, M. Cognitive impairment and psychosis in schizophrenia: Independent or linked conditions? World Psychiatry 2019, 18, 162-163. [CrossRef] [PubMed]

15. Bleuler, E. Dementia Praecox, or the Group of Schizophrenias; International Universities Press: New York, NY, USA, 1950.

16. Heinrichs, R.W.; Zakzanis, K.K. Neurocognitive deficit in schizophrenia: A quantitative review of the evidence. Neuropsychology 1998, 12, 426-445. [CrossRef] [PubMed]

17. Mesholam-Gately, R.I.; Giuliano, A.J.; Goff, K.P.; Faraone, S.V.; Seidman, L.J. Neurocognition in first-episode schizophrenia: A meta-analytic review. Neuropsychology 2009, 23, 315-336. [CrossRef] [PubMed]

18. Reichenberg, A. The assessment of neuropsychological functioning in schizophrenia. Dialogues Clin. Neurosci. 2010, 12, 383-392. [CrossRef]

19. Fatouros-Bergman, H.; Cervenka, S.; Flyckt, L.; Edman, G.; Farde, L. Meta-analysis of cognitive performance in drug-naïve patients with schizophrenia. Schizophr. Res. 2014, 158, 156-162. [CrossRef] [PubMed]

20. Zhang, H.; Wang, Y.; Hu, Y.; Zhu, Y.; Zhang, T.; Wang, J.; Ma, K.; Shi, C.; Yu, X.; Li, C. Meta-analysis of cognitive function in Chinese first-episode schizophrenia: MATRICS Consensus Cognitive Battery (MCCB) profile of impairment. Gen. Psychiatry 2019, 32, e100043. [CrossRef] [PubMed]

21. Bora, E.; Murray, R.M. Meta-analysis of cognitive deficits in ultra-high risk to psychosis and first-episode psychosis: Do the cognitive deficits progress over, or after, the onset of psychosis? Schizophr. Bull. 2014, 40, 744-755. [CrossRef] [PubMed]

22. Sitskoorn, M.M.; Aleman, A.; Ebisch, S.J.; Appels, M.C.; Kahn, R.S. Cognitive deficits in relatives of patients with schizophrenia: A meta-analysis. Schizophr. Res. 2004, 71, 285-295. [CrossRef] [PubMed]

23. Mucci, A.; Galderisi, S.; Green, M.F.; Nuechterlein, K.; Rucci, P.; Gibertoni, D.; Rossi, A.; Rocca, P.; Bertolino, A.; Bucci, P.; et al. Familial aggregation of MATRICS Consensus Cognitive Battery scores in a large sample of outpatients with schizophrenia and their unaffected relatives. Psychol. Med. 2017, 48, 1359-1366. [CrossRef] [PubMed]

24. McCleery, A.; Ventura, J.; Kern, R.S.; Subotnik, K.L.; Gretchen-Doorly, D.; Green, M.F.; Hellemann, G.S.; Nuechterlein, K.H. Cognitive functioning in first-episode schizophrenia: MATRICS Consensus Cognitive Battery (MCCB) Profile of Impairment. Schizophr. Res. 2014, 157, 33-39. [CrossRef] [PubMed]

25. Kotov, R.; Jonas, K.G.; Carpenter, W.T.; Dretsch, M.N.; Eaton, N.R.; Forbes, M.K.; Forbush, K.T.; Hobbs, K.; Reininghaus, U.; Slade, T.; et al. Validity and utility of Hierarchical Taxonomy of Psychopathology (HiTOP): I. Psychosis superspectrum. World Psychiatry 2020, 19, 151-172. [CrossRef]

26. Glenthøj, L.B.; Mariegaard, L.S.; Fagerlund, B.; Jepsen, J.R.M.; Kristensen, T.D.; Wenneberg, C.; Krakauer, K.; Medalia, A.; Roberts, D.L.; Hjorthøj, C.; et al. Effectiveness of cognitive remediation in the ultra-high risk state for psychosis. World Psychiatry 2020, 19, 401-402. [CrossRef]

27. Heckers, S.; Kendler, K.S. The evolution of Kraepelin's nosological principles. World Psychiatry 2020, 19, 381-388. [CrossRef] [PubMed]

28. Green, M.F.; Kern, R.S.; Heaton, R.K. Longitudinal studies of cognition and functional outcome in schizophrenia: Implications for MATRICS. Schizophr. Res. 2004, 72, 41-51. [CrossRef]

29. Thai, M.L.; Andreassen, A.K.; Bliksted, V. A meta-analysis of executive dysfunction in patients with schizophrenia: Different degree of impairment in the ecological subdomains of the Behavioural Assessment of the Dysexecutive Syndrome. Psychiatry Res. 2019, 272, 230-236. [CrossRef]

30. Melle, I. Cognition in schizophrenia: A marker of underlying neurodevelopmental problems? World Psychiatry 2019, 18, 164-165. [CrossRef]

31. Reininghaus, U.; Böhnke, J.R.; Chavez-Baldini, U.; Gibbons, R.; Ivleva, E.; Clementz, B.A.; Pearlson, G.D.; Keshavan, M.S.; Sweeney, J.A.; Tamminga, C.A. Transdiagnostic dimensions of psychosis in the Bipolar-Schizophrenia Network on Intermediate Phenotypes (B-SNIP). World Psychiatry 2019, 18, 67-76. [CrossRef]

32. Guloksuz, S.; Pries, L.K.; Delespaul, P.; Kenis, G.; Luykx, J.J.; Lin, B.D.; Richards, A.L.; Akdede, B.; Binbay, T.; Altınyazar, V.; et al. Examining the independent and joint effects of molecular genetic liability and environmental exposures in schizophrenia: Results from the EUGEI study. World Psychiatry 2019, 18, 173-182. [CrossRef] [PubMed]

33. Menon, V. Brain networks and cognitive impairment in psychiatric disorders. World Psychiatry 2020, 19, 309-310. [CrossRef]

34. Insel, T.R. Rethinking schizophrenia. Nature 2010, 468, 187-193. [CrossRef]

35. Tripathi, A.; Kar, S.K.; Shukla, R. Cognitive Deficits in Schizophrenia: Understanding the Biological Correlates and Remediation Strategies. Clin. Psychopharmacol. Neurosci. 2018, 16, 7-17. [CrossRef] [PubMed]

36. Gourion, D.; Goldberger, C.; Olie, J.P.; Lôo, H.; Krebs, M.O. Neurological and morphological anomalies and the genetic liability to schizophrenia: A composite phenotype. Schizophr. Res. 2004, 67, 23-31. [CrossRef]

37. Kirkpatrick, B.; Fischer, B. Subdomains Within the Negative Symptoms of Schizophrenia: Commentary. Schizophr. Bull. 2006, 32, 246-249. [CrossRef] [PubMed]

38. Galderisi, S.; Mucci, A.; Dollfus, S.; Nordentoft, M.; Falkai, P.; Kaiser, S.; Giordano, G.M.; Vandevelde, A.; Nielsen, M.; Glenthøj, L.B.; et al. EPA guidance on assessment of negative symptoms in schizophrenia. Eur. Psychiatry 2021, 64, e23. [CrossRef] 
39. Galderisi, S.; Färden, A.; Kaiser, S. Dissecting negative symptoms of schizophrenia: History, assessment, pathophysiological mechanisms and treatment. Schizophr. Res. 2017, 186, 1-2. [CrossRef] [PubMed]

40. Galderisi, S.; Mucci, A.; Buchanan, R.W.; Arango, C. Negative symptoms of schizophrenia: New developments and unanswered research questions. Lancet Psychiatry 2018, 5, 664-677. [CrossRef]

41. Kirkpatrick, B.; Fenton, W.S.; Carpenter, W.T., Jr.; Marder, S.R. The NIMH-MATRICS consensus statement on negative symptoms. Schizophr. Bull. 2006, 32, 214-219. [CrossRef]

42. Marder, S.R.; Galderisi, S. The current conceptualization of negative symptoms in schizophrenia. World Psychiatry 2017, 16, 14-24. [CrossRef]

43. Correll, C.U.; Schooler, N.R. Negative Symptoms in Schizophrenia: A Review and Clinical Guide for Recognition, Assessment, and Treatment. Neuropsychiatr. Dis. Treat. 2020, 16, 519-534. [CrossRef]

44. Reed, G.M.; First, M.B.; Kogan, C.S.; Hyman, S.E.; Gureje, O.; Gaebel, W.; Maj, M.; Stein, D.J.; Maercker, A.; Tyrer, P.; et al. Innovations and changes in the ICD-11 classification of mental, behavioural and neurodevelopmental disorders. World Psychiatry 2019, 18, 3-19. [CrossRef] [PubMed]

45. Gaebel, W.; Falkai, P.; Hasan, A. The revised German evidence- and consensus-based schizophrenia guideline. World Psychiatry 2020, 19, 117-119. [CrossRef] [PubMed]

46. Gard, D.E.; Kring, A.M.; Gard, M.G.; Horan, W.P.; Green, M.F. Anhedonia in schizophrenia: Distinctions between anticipatory and consummatory pleasure. Schizophr. Res. 2007, 93, 253-260. [CrossRef] [PubMed]

47. Heerey, E.A.; Gold, J.M. Patients with schizophrenia demonstrate dissociation between affective experience and motivated behavior. J. Abnorm. Psychol. 2007, 116, 268-278. [CrossRef]

48. Heerey, E.A.; Robinson, B.M.; McMahon, R.P.; Gold, J.M. Delay discounting in schizophrenia. Cogn. Neuropsychiatry 2007, 12, 213-221. [CrossRef] [PubMed]

49. Waltz, J.A.; Frank, M.J.; Robinson, B.M.; Gold, J.M. Selective reinforcement learning deficits in schizophrenia support predictions from computational models of striatal-cortical dysfunction. Biol. Psychiatry 2007, 62, 756-764. [CrossRef]

50. Kring, A.M.; Moran, E.K. Emotional response deficits in schizophrenia: Insights from affective science. Schizophr. Bull. 2008, 34, 819-834. [CrossRef]

51. Barch, D.M.; Dowd, E.C. Goal representations and motivational drive in schizophrenia: The role of prefrontal-striatal interactions. Schizophr. Bull. 2010, 36, 919-934. [CrossRef] [PubMed]

52. Cohen, A.S.; Minor, K.S. Emotional experience in patients with schizophrenia revisited: Meta-analysis of laboratory studies. Schizophr. Bull. 2010, 36, 143-150. [CrossRef]

53. Dowd, E.C.; Barch, D.M. Anhedonia and emotional experience in schizophrenia: Neural and behavioral indicators. Biol. Psychiatry 2010, 67, 902-911. [CrossRef] [PubMed]

54. Foussias, G.; Remington, G. Negative symptoms in schizophrenia: Avolition and Occam's razor. Schizophr. Bull. 2010, 36, 359-369. [CrossRef]

55. Pizzagalli, D.A. The "anhedonia paradox" in schizophrenia: Insights from affective neuroscience. Biol. Psychiatry 2010, 67, 899-901. [CrossRef] [PubMed]

56. Simpson, E.H.; Waltz, J.A.; Kellendonk, C.; Balsam, P.D. Schizophrenia in translation: Dissecting motivation in schizophrenia and rodents. Schizophr. Bull. 2012, 38, 1111-1117. [CrossRef] [PubMed]

57. Mann, C.L.; Footer, O.; Chung, Y.S.; Driscoll, L.L.; Barch, D.M. Spared and impaired aspects of motivated cognitive control in schizophrenia. J. Abnorm. Psychol. 2013, 122, 745-755. [CrossRef] [PubMed]

58. Strauss, G.P.; Cohen, A.S. A Transdiagnostic Review of Negative Symptom Phenomenology and Etiology. Schizophr. Bull. 2017, 43, 712-719. [CrossRef]

59. Strauss, G.P.; Waltz, J.A.; Gold, J.M. A review of reward processing and motivational impairment in schizophrenia. Schizophr. Bull. 2014, 40, S107-S116. [CrossRef] [PubMed]

60. Morris, R.W.; Quail, S.; Griffiths, K.R.; Green, M.J.; Balleine, B.W. Corticostriatal control of goal-directed action is impaired in schizophrenia. Biol. Psychiatry 2015, 77, 187-195. [CrossRef] [PubMed]

61. Mucci, A.; Dima, D.; Soricelli, A.; Volpe, U.; Bucci, P.; Frangou, S.; Prinster, A.; Salvatore, M.; Galderisi, S.; Maj, M. Is avolition in schizophrenia associated with a deficit of dorsal caudate activity? A functional magnetic resonance imaging study during reward anticipation and feedback. Psychol. Med. 2015, 45, 1765-1778. [CrossRef]

62. Amodio, A.; Quarantelli, M.; Mucci, A.; Prinster, A.; Soricelli, A.; Vignapiano, A.; Giordano, G.M.; Merlotti, E.; Nicita, A.; Galderisi, S. Avolition-Apathy and White Matter Connectivity in Schizophrenia: Reduced Fractional Anisotropy Between Amygdala and Insular Cortex. Clin. EEG Neurosci. 2018, 49, 55-65. [CrossRef] [PubMed]

63. Giordano, G.M.; Stanziano, M.; Papa, M.; Mucci, A.; Prinster, A.; Soricelli, A.; Galderisi, S. Functional connectivity of the ventral tegmental area and avolition in subjects with schizophrenia: A resting state functional MRI study. Eur. Neuropsychopharmacol. 2018, 28, 589-602. [CrossRef] [PubMed]

64. Culbreth, A.J.; Moran, E.K.; Kandala, S.; Westbrook, A.; Barch, D.M. Effort, avolition and motivational experience in schizophrenia: Analysis of behavioral and neuroimaging data with relationships to daily motivational experience. Clin. Psychol. Sci. 2020, 8 , 555-568. [CrossRef] [PubMed]

65. Kaiser, S.; Lyne, J.; Agartz, I.; Clarke, M.; Mørch-Johnsen, L.; Faerden, A. Individual negative symptoms and domains -Relevance for assessment, pathomechanisms and treatment. Schizophr. Res. 2017, 186, 39-45. [CrossRef] [PubMed] 
66. Harvey, P.D.; Strassnig, M.T. Cognition and disability in schizophrenia: Cognition-related skills deficits and decision-making challenges add to morbidity. World Psychiatry 2019, 18, 165-167. [CrossRef]

67. Grant, P.M.; Best, M.W.; Beck, A.T. The meaning of group differences in cognitive test performance. World Psychiatry 2019, 18, 163-164. [CrossRef]

68. Moritz, S.; Silverstein, S.M.; Dietrichkeit, M.; Gallinat, J. Neurocognitive deficits in schizophrenia are likely to be less severe and less related to the disorder than previously thought. World Psychiatry 2020, 19, 254-255. [CrossRef]

69. Bissonette, G.B.; Roesch, M.R. Development and function of the midbrain dopamine system: What we know and what we need to. Genes Brain Behav. 2016, 15, 62-73. [CrossRef] [PubMed]

70. Bromberg-Martin, E.S.; Matsumoto, M.; Hikosaka, O. Dopamine in motivational control: Rewarding, aversive, and alerting. Neuron 2010, 68, 815-834. [CrossRef] [PubMed]

71. O'Doherty, J.P. Multiple Systems for the Motivational Control of Behavior and Associated Neural Substrates in Humans. Curr. Top. Behav. Neurosci. 2016, 27, 291-312. [CrossRef] [PubMed]

72. Bowie, C.R. Cognitive remediation for severe mental illness: State of the field and future directions. World Psychiatry 2019, 18, 274-275. [CrossRef]

73. Levy, R.; Dubois, B. Apathy and the functional anatomy of the prefrontal cortex-basal ganglia circuits. Cereb. Cortex 2006, 16, 916-928. [CrossRef] [PubMed]

74. Faerden, A.; Vaskinn, A.; Finset, A.; Agartz, I.; Ann Barrett, E.; Friis, S.; Simonsen, C.; Andreassen, O.A.; Melle, I. Apathy is associated with executive functioning in first episode psychosis. BMC Psychiatry 2009, 9, 1. [CrossRef] [PubMed]

75. Hartmann-Riemer, M.N.; Hager, O.M.; Kirschner, M.; Bischof, M.; Kluge, A.; Seifritz, E.; Kaiser, S. The association of neurocognitive impairment with diminished expression and apathy in schizophrenia. Schizophr. Res. 2015, 169, 427-432. [CrossRef] [PubMed]

76. Kring, A.M.; Elis, O. Emotion deficits in people with schizophrenia. Annu. Rev. Clin. Psychol. 2013, 9, 409-433. [CrossRef] [PubMed]

77. Cohen, A.S.; Schwartz, E.; Le, T.P.; Fedechko, T.; Kirkpatrick, B.; Strauss, G.P. Using biobehavioral technologies to effectively advance research on negative symptoms. World Psychiatry 2019, 18, 103-104. [CrossRef]

78. Miller, E.K.; Cohen, J.D. An integrative theory of prefrontal cortex function. Annu. Rev. Neurosci. 2001, 24, 167-202. [CrossRef]

79. İnce, E.; Üçok, A. Relationship Between Persistent Negative Symptoms and Findings of Neurocognition and Neuroimaging in Schizophrenia. Clin. EEG Neurosci. 2017, 49, 27-35. [CrossRef]

80. Hasey, G.M.; Kiang, M. A review of recent literature employing electroencephalographic techniques to study the pathophysiology, phenomenology, and treatment response of schizophrenia. Curr. Psychiatry Rep. 2013, 15, 388. [CrossRef] [PubMed]

81. Qiu, Y.-Q.; Tang, Y.-X.; Chan, R.C.K.; Sun, X.-Y.; He, J. P300 aberration in first-episode schizophrenia patients: A meta-analysis. PLoS ONE 2014, 9, e97794. [CrossRef]

82. Phillips, J.M.; Maxwell, C.R.; Ehrlichman, R.S.; Siegel, S.J. Event-Related Potentials (ERPs) in the Study of Schizophrenia: How Preclinical ERP Studies have Contributed to our Understanding of Schizophrenia. In Handbook of Neurochemistry and Molecular Neurobiology: Schizophrenia; Lajtha, A., Javitt, D., Kantrowitz, J., Eds.; Springer: Boston, MA, USA, 2009; pp. 525-543.

83. Turetsky, B.I.; Bilker, W.B.; Siegel, S.J.; Kohler, C.G.; Gur, R.E. Profile of auditory information-processing deficits in schizophrenia. Psychiatry Res. 2009, 165, 27-37. [CrossRef] [PubMed]

84. Huang, W.J.; Chen, W.W.; Zhang, X. The neurophysiology of P 300-An integrated review. Eur. Rev. Med Pharmacol. Sci. 2015, 19, 1480-1488. [PubMed]

85. Wang, L.; Zheng, J.; Huang, S.; Sun, H. P300 and Decision Making under Risk and Ambiguity. Comput. Intell. Neurosci. 2015, 2015, 108417. [CrossRef]

86. Chen, Y.; Xu, J.; Zhou, L.; Zheng, Y. The time course of incentive processing in anticipatory and consummatory anhedonia. $J$. Affect. Disord. 2018, 238, 442-450. [CrossRef] [PubMed]

87. Broyd, S.J.; Richards, H.J.; Helps, S.K.; Chronaki, G.; Bamford, S.; Sonuga-Barke, E.J. An electrophysiological monetary incentive delay (e-MID) task: A way to decompose the different components of neural response to positive and negative monetary reinforcement. J. Neurosci. Methods 2012, 209, 40-49. [CrossRef] [PubMed]

88. Vignapiano, A.; Mucci, A.; Ford, J.; Montefusco, V.; Plescia, G.M.; Bucci, P.; Galderisi, S. Reward anticipation and trait anhedonia: An electrophysiological investigation in subjects with schizophrenia. Clin. Neurophysiol. 2016, 127, 2149-2160. [CrossRef] [PubMed]

89. Pfabigan, D.M.; Seidel, E.-M.; Sladky, R.; Hahn, A.; Paul, K.; Grahl, A.; Küblböck, M.; Kraus, C.; Hummer, A.; Kranz, G.S.; et al. P300 amplitude variation is related to ventral striatum BOLD response during gain and loss anticipation: An EEG and fMRI experiment. NeuroImage 2014, 96, 12-21. [CrossRef] [PubMed]

90. Megías, A.; Gutiérrez-Cobo, M.J.; Gómez-Leal, R.; Cabello, R.; Fernández-Berrocal, P. Performance on emotional tasks engaging cognitive control depends on emotional intelligence abilities: An ERP study. Sci. Rep. 2017, 7, 16446. [CrossRef] [PubMed]

91. Portnova, G.V.; Maslennikova, A.V.; Zakharova, N.V.; Martynova, O.V. The Deficit of Multimodal Perception of Congruent and Non-Congruent Fearful Expressions in Patients with Schizophrenia: The ERP Study. Brain Sci. 2021, 11, 96. [CrossRef]

92. Polich, J. Updating P300: An integrative theory of P3a and P3b. Clin. Neurophysiol. 2007, 118, 2128-2148. [CrossRef] 
93. Bledowski, C.; Prvulovic, D.; Hoechstetter, K.; Scherg, M.; Wibral, M.; Goebel, R.; Linden, D.E.J. Localizing P300 Generators in Visual Target and Distractor Processing: A Combined Event-Related Potential and Functional Magnetic Resonance Imaging Study. J. Neurosci. 2004, 24, 9353. [CrossRef] [PubMed]

94. Linden, D.E. The p300: Where in the brain is it produced and what does it tell us? Neurosci. A Rev. J. Bringing Neurobiol. Neurol. Psychiatry 2005, 11, 563-576. [CrossRef] [PubMed]

95. Onitsuka, T.; Oribe, N.; Nakamura, I.; Kanba, S. Review of neurophysiological findings in patients with schizophrenia. Psychiatry Clin. Neurosci. 2013, 67, 461-470. [CrossRef]

96. Galderisi, S.; Mucci, A.; Volpe, U.; Boutros, N. Evidence-based medicine and electrophysiology in schizophrenia. Clin. EEG Neurosci. 2009, 40, 62-77. [CrossRef] [PubMed]

97. Jeon, Y.W.; Polich, J. Meta-analysis of P300 and schizophrenia: Patients, paradigms, and practical implications. Psychophysiology 2003, 40, 684-701. [CrossRef]

98. Perrottelli, A.; Giordano, G.M.; Brando, F.; Giuliani, L.; Mucci, A. EEG-Based Measures in At-Risk Mental State and Early Stages of Schizophrenia: A Systematic Review. Front. Psychiatry 2021, 12, 582. [CrossRef]

99. Walhovd, K.B.; Rosquist, H.; Fjell, A.M. P300 amplitude age reductions are not caused by latency jitter. Psychophysiology 2008, 45, 545-553. [CrossRef] [PubMed]

100. Mott, K.K.; Alperin, B.R.; Holcomb, P.J.; Daffner, K.R. Age-related decline in differentiated neural responses to rare target versus frequent standard stimuli. Brain Res. 2014, 1587, 97-111. [CrossRef] [PubMed]

101. Porcaro, C.; Balsters, J.H.; Mantini, D.; Robertson, I.H.; Wenderoth, N. P3b amplitude as a signature of cognitive decline in the older population: An EEG study enhanced by Functional Source Separation. NeuroImage 2019, 184, 535-546. [CrossRef] [PubMed]

102. Andersen, E.H.; Campbell, A.M.; Schipul, S.E.; Bellion, C.M.; Donkers, F.C.; Evans, A.M.; Belger, A. Electrophysiological Correlates of Aberrant Motivated Attention and Salience Processing in Unaffected Relatives of Schizophrenia Patients. Clin. EEG Neurosci. 2016, 47, 11-23. [CrossRef] [PubMed]

103. Heidrich, A.; Strik, W.K. Auditory P300 topography and neuropsychological test performance: Evidence for left hemispheric dysfunction in schizophrenia. Biol. Psychiatry 1997, 41, 327-335. [CrossRef]

104. Schreiber, H.; Stolz-Born, G.; Kornhuber, H.H.; Born, J. Investigation of electrophysiological correlates of attention and information processing as vulnerability indicators for schizophrenia. J. Psychophysiol. 1997, 3, 286-300.

105. Kruiper, C.; Fagerlund, B.; Nielsen, M.Ø.; Düring, S.; Jensen, M.H.; Ebdrup, B.H.; Glenthøj, B.Y.; Oranje, B. Associations between P3a and P3b amplitudes and cognition in antipsychotic-naïve first-episode schizophrenia patients. Psychol. Med. 2019, 49, 868-875. [CrossRef]

106. Nagasawa, T.; Kamiya, T.; Kawasaki, Y.; Higashima, M.; Urata, K.; Sakai, N.; Koshino, Y. The relationship between auditory ERP and neuropsychological assessments in schizophrenia. Int. J. Psychophysiol. 1999, 34, 267-274. [CrossRef]

107. Sumich, A.; Kumari, V.; Dodd, P.; Ettinger, U.; Hughes, C.; Zachariah, E.; Sharma, T. N100 and P300 amplitude to Go and No-Go variants of the auditory oddball in siblings discordant for schizophrenia. Schizophr. Res. 2008, 98, 265-277. [CrossRef] [PubMed]

108. Chang, W.-H.; Chen, K.-C.; Yang, Y.-K.; Chen, P.-S.; Lu, R.-B.; Yeh, T.-L.; Wang, C.S.-M.; Lee, I.H. Association between auditory P300, psychopathology, and memory function in drug-naïve schizophrenia. Kaohsiung J. Med. Sci. 2014, 30, 133-138. [CrossRef] [PubMed]

109. Galletly, C.A.; MacFarlane, A.C.; Clark, C.R. Impaired updating of working memory in schizophrenia. Int. J. Psychophysiol. 2007, 63, 265-274. [CrossRef] [PubMed]

110. Bruder, G.E.; Kayser, J.; Tenke, C.E.; Friedman, M.; Malaspina, D.; Gorman, J.M. Event-related potentials in schizophrenia during tonal and phonetic oddball tasks: Relations to diagnostic subtype, symptom features and verbal memory. Biol. Psychiatry 2001, 50, 447-452. [CrossRef]

111. Kayser, J.; Bruder, G.E.; Friedman, D.; Tenke, C.E.; Amador, X.F.; Clark, S.C.; Malaspina, D.; Gorman, J.M. Brain event-related potentials (ERPs) in schizophrenia during a word recognition memory task. Int. J. Psychophysiol. 1999, 34, 249-265. [CrossRef]

112. Nieman, D.H.; Koelman, J.H.T.M.; Linszen, D.H.; Bour, L.J.; Dingemans, P.M.; Ongerboer de Visser, B.W. Clinical and neuropsychological correlates of the P300 in schizophrenia. Schizophr. Res. 2002, 55, 105-113. [CrossRef]

113. Shajahan, P.M.; O'Carroll, R.E.; Glabus, M.F.; Ebmeier, K.P.; Blackwood, D.H. Correlation of auditory 'oddball’ P300 with verbal memory deficits in schizophrenia. Psychol. Med. 1997, 27, 579-586. [CrossRef]

114. Kim, M.; Lee, T.H.; Kim, J.-H.; Hong, H.; Lee, T.Y.; Lee, Y.; Salisbury, D.F.; Kwon, J.S. Decomposing P300 into correlates of genetic risk and current symptoms in schizophrenia: An inter-trial variability analysis. Schizophr. Res. 2018, 192, 232-239. [CrossRef]

115. Şevik, A.E.; Anıl Yağcığlu, A.E.; Yağcığlu, S.; Karahan, S.; Gürses, N.; Yıldız, M. Neuropsychological performance and auditory event related potentials in schizophrenia patients and their siblings: A family study. Schizophr. Res. 2011, 130, 195-202. [CrossRef]

116. Ertekin, E.; Üçok, A.; Keskin-Ergen, Y.; Devrim-Üçok, M. Deficits in Go and NoGo P3 potentials in patients with schizophrenia. Psychiatry Res. 2017, 254, 126-132. [CrossRef]

117. Kim, M.-S.; Kang, S.-S.; Youn, T.; Kang, D.-H.; Kim, J.-J.; Kwon, J.S. Neuropsychological correlates of P300 abnormalities in patients with schizophrenia and obsessive-compulsive disorder. Psychiatry Res. Neuroimag. 2003, 123, 109-123. [CrossRef]

118. Liu, Z.; Tam, W.C.; Xue, Z.; Yao, S.; Wu, D. Positive and negative symptom profile schizophrenia and abnormalities in the P300 component of the event-related potential: A longitudinal controlled study. Psychiatry Res. 2004, 132, 131-139. [CrossRef] [PubMed] 
119. Mathalon, D.H.; Ford, J.M.; Pfefferbaum, A. Trait and state aspects of P300 amplitude reduction in schizophrenia: A retrospective longitudinal study. Biol. Psychiatry 2000, 47, 434-449. [CrossRef]

120. Salgari, G.C.; Potts, G.F.; Schmidt, J.; Chan, C.C.; Spencer, C.C.; Bedwell, J.S. Event-related potentials to rare visual targets and negative symptom severity in a transdiagnostic psychiatric sample. Clin. Neurophysiol. 2021, 132, 1526-1536. [CrossRef] [PubMed]

121. Hamilton, H.K.; Woods, S.W.; Roach, B.J.; Llerena, K.; McGlashan, T.H.; Srihari, V.H.; Ford, J.M.; Mathalon, D.H. Auditory and Visual Oddball Stimulus Processing Deficits in Schizophrenia and the Psychosis Risk Syndrome: Forecasting Psychosis Risk With P300. Schizophr. Bull. 2019, 45, 1068-1080. [CrossRef]

122. Van Tricht, M.J.; Nieman, D.H.; Koelman, J.H.T.M.; van der Meer, J.N.; Bour, L.J.; de Haan, L.; Linszen, D.H. Reduced Parietal P300 Amplitude is Associated with an Increased Risk for a First Psychotic Episode. Biol. Psychiatry 2010, 68, 642-648. [CrossRef]

123. Lee, S.Y.; Namkoong, K.; Cho, H.H.; Song, D.-H.; An, S.K. Reduced visual P300 amplitudes in individuals at ultra-high risk for psychosis and first-episode schizophrenia. Neurosci. Lett. 2010, 486, 156-160. [CrossRef]

124. Mori, K.; Morita, K.; Shoji, Y.; Matsuoka, T.; Fujiki, R.; Uchimura, N. State and trait markers of emotionally charged visual event-related potentials (P300) in drug-naïve schizophrenia. Psychiatry Clin. Neurosci. 2012, 66, 261-269. [CrossRef] [PubMed]

125. Sumich, A.; Harris, A.; Flynn, G.; Whitford, T.; Tunstall, N.; Kumari, V.; Brammer, M.; Gordon, E.; Williams, L.M. Event-related potential correlates of depression, insight and negative symptoms in males with recent-onset psychosis. Clin. Neurophysiol. 2006, 117, 1715-1727. [CrossRef] [PubMed]

126. Meisenzahl, E.M.; Frodl, T.; Müller, D.; Schmitt, G.; Gallinat, J.; Zetzsche, T.; Marcuse, A.; Juckel, G.; Leinsinger, G.; Hahn, K.; et al. Superior temporal gyrus and P300 in schizophrenia: A combined ERP/structural magnetic resonance imaging investigation. J. Psychiatr. Res. 2004, 38, 153-162. [CrossRef]

127. Mucci, A.; Galderisi, S.; Kirkpatrick, B.; Bucci, P.; Volpe, U.; Merlotti, E.; Centanaro, F.; Catapano, F.; Maj, M. Double dissociation of N1 and P3 abnormalities in deficit and nondeficit schizophrenia. Schizophr. Res. 2007, 92, 252-261. [CrossRef] [PubMed]

128. Kay, S.R.; Fiszbein, A.; Opler, L.A. The positive and negative syndrome scale (PANSS) for schizophrenia. Schizophr. Bull. 1987, 13, 261-276. [CrossRef] [PubMed]

129. Andreasen, N.C. Scale for the Assessment of Negative Symptoms (SANS). Br. J. Psychiatry 1989, 155, 53-58. [CrossRef]

130. Overall, J.E.; Gorham, D.R. The Brief Psychiatric Rating Scale. Psychol. Rep. 1962, 10, 799-812. [CrossRef]

131. Kirkpatrick, B.; Strauss, G.P.; Nguyen, L.; Fischer, B.A.; Daniel, D.G.; Cienfuegos, A.; Marder, S.R. The Brief Negative Symptom Scale: Psychometric Properties. Schizophr. Bull. 2010, 37, 300-305. [CrossRef]

132. Mucci, A.; Galderisi, S.; Merlotti, E.; Rossi, A.; Rocca, P.; Bucci, P.; Piegari, G.; Chieffi, M.; Vignapiano, A.; Maj, M. The Brief Negative Symptom Scale (BNSS): Independent validation in a large sample of Italian patients with schizophrenia. Eur. Psychiatry 2015, 30, 641-647. [CrossRef] [PubMed]

133. Addington, D.; Addington, J.; Schissel, B. A depression rating scale for schizophrenics. Schizophr. Res. 1990, 3, 247-251. [CrossRef]

134. Gerlach, J.; Korsgaard, S.; Clemmesen, P.; Lauersen, A.M.; Magelund, G.; Noring, U.; Povlsen, U.J.; Bech, P.; Casey, D.E. The St. Hans Rating Scale for extrapyramidal syndromes: Reliability and validity. Acta Psychiatr. Scand. 1993, 87, 244-252. [CrossRef] [PubMed]

135. Nuechterlein, K.H.; Green, M.F.; Kern, R.S.; Baade, L.E.; Barch, D.M.; Cohen, J.D.; Essock, S.; Fenton, W.S.; Frese, F.J., 3rd; Gold, J.M.; et al. The MATRICS Consensus Cognitive Battery, part 1: Test selection, reliability, and validity. Am. J. Psychiatry 2008, 165, 203-213. [CrossRef]

136. Comerchero, M.D.; Polich, J. P3a and P3b from typical auditory and visual stimuli. Clin. Neurophysiol. 1999, 110, 24-30. [CrossRef]

137. Bachiller, A.; Romero, S.; Molina, V.; Alonso, J.F.; Mañanas, M.A.; Poza, J.; Hornero, R. Auditory P3a and P3b neural generators in schizophrenia: An adaptive sLORETA P300 localization approach. Schizophr. Res. 2015, 169, 318-325. [CrossRef] [PubMed]

138. Kim, D.-W.; Shim, M.; Kim, J.-I.; Im, C.-H.; Lee, S.-H. Source Activation of P300 Correlates with Negative Symptom Severity in Patients with Schizophrenia. Brain Topogr. 2014, 27, 307-317. [CrossRef] [PubMed]

139. Molina, V.; Bachiller, A.; de Luis, R.; Lubeiro, A.; Poza, J.; Hornero, R.; Alonso, J.F.; Mañanas, M.A.; Marqués, P.; Romero, S. Topography of activation deficits in schizophrenia during P300 task related to cognition and structural connectivity. Eur. Arch. Psychiatry Clin. Neurosci. 2019, 269, 419-428. [CrossRef] [PubMed]

140. Van der Stelt, O.; Lieberman, J.A.; Belger, A. Auditory P300 in high-risk, recent-onset and chronic schizophrenia. Schizophr. Res. 2005, 77, 309-320. [CrossRef]

141. Morales-Muñoz, I.; Jurado-Barba, R.; Fernández-Guinea, S.; Álvarez-Alonso, M.J.; Rodríguez-Jiménez, R.; Jiménez-Arriero, M.A.; Rubio, G. Cognitive impairments in patients with first episode psychosis: The relationship between neurophysiological and neuropsychological assessments. J. Clin. Neurosci. 2017, 36, 80-87. [CrossRef] [PubMed]

142. Dosenbach, N.U.; Fair, D.A.; Cohen, A.L.; Schlaggar, B.L.; Petersen, S.E. A dual-networks architecture of top-down control. Trends Cogn. Sci. 2008, 12, 99-105. [CrossRef]

143. Tam, A.; Luedke, A.C.; Walsh, J.J.; Fernandez-Ruiz, J.; Garcia, A. Effects of reaction time variability and age on brain activity during Stroop task performance. Brain Imaging Behav. 2015, 9, 609-618. [CrossRef] [PubMed]

144. Carter, J.D.; Bizzell, J.; Kim, C.; Bellion, C.; Carpenter, K.L.H.; Dichter, G.; Belger, A. Attention deficits in schizophreniaPreliminary evidence of dissociable transient and sustained deficits. Schizophr. Res. 2010, 122, 104-112. [CrossRef] [PubMed]

145. Dichter, G.S.; Bellion, C.; Casp, M.; Belger, A. Impaired Modulation of Attention and Emotion in Schizophrenia. Schizophr. Bull. 2008, 36, 595-606. [CrossRef] 
146. Li, F.; Wang, J.; Jiang, Y.; Si, Y.; Peng, W.; Song, L.; Jiang, Y.; Zhang, Y.; Dong, W.; Yao, D.; et al. Top-Down Disconnectivity in Schizophrenia During P300 Tasks. Front. Comput. Neurosci. 2018, 12, 33. [CrossRef] [PubMed]

147. O'Donnell, B.F.; McCarley, R.W.; Potts, G.F.; Salisbury, D.F.; Nestor, P.G.; Hirayasu, Y.; Niznikiewicz, M.A.; Barnard, J.; Shen, Z.J.; Weinstein, D.M.; et al. Identification of neural circuits underlying P300 abnormalities in schizophrenia. Psychophysiology 1999, 36, 388-398. [CrossRef]

148. Sabeti, M.; Moradi, E.; Katebi, S. Analysis of Neural Sources of P300 Event-Related Potential in Normal and Schizophrenic Participants. In Software Tools and Algorithms for Biological Systems; Arabnia, H.R., Tran, Q.-N., Eds.; Springer: New York, NY, USA, 2011; pp. 589-597.

149. Van Dinteren, R.; Arns, M.; Jongsma, M.L.; Kessels, R.P. Combined frontal and parietal P300 amplitudes indicate compensated cognitive processing across the lifespan. Front. Aging Neurosci. 2014, 6, 294. [CrossRef] [PubMed]

150. Polich, J. On the relationship between EEG and P300: Individual differences, aging, and ultradian rhythms. Int. J. Psychophysiol. 1997, 26, 299-317. [CrossRef]

151. Walhovd, K.B.; Fjell, A.M. Two- and three-stimuli auditory oddball ERP tasks and neuropsychological measures in aging. NeuroReport 2001, 12, 314-3153. [CrossRef]

152. Fjell, A.M.; Walhovd, K.B.; Fischl, B.; Reinvang, I. Cognitive function, P3a/P3b brain potentials, and cortical thickness in aging. Hum. Brain Mapp. 2007, 28, 1098-1116. [CrossRef]

153. Kawasaki, Y.; Sumiyoshi, T.; Higuchi, Y.; Ito, T.; Takeuchi, M.; Kurachi, M. Voxel-based analysis of P300 electrophysiological topography associated with positive and negative symptoms of schizophrenia. Schizophr. Res. 2007, 94, 164-171. [CrossRef] 